\title{
TU/e Emphoven

\section{Planar circularly symmetric EBG's to improve the isolation of array elements}

\section{Citation for published version (APA):}

Llombart, N., Neto, A., Gerini, G., \& de Maagt, P. J. I. (2005). Planar circularly symmetric EBG's to improve the isolation of array elements. In Proceedings of the 2005 IEEE Antennas and Propagation Society International Symposium, 3-8 July 2005, Washington, DC (pp. 582-585). Institute of Electrical and Electronics Engineers. https://doi.org/10.1109/APS.2005.1551877

DOI:

10.1109/APS.2005.1551877

Document status and date:

Published: 01/01/2005

\section{Document Version:}

Publisher's PDF, also known as Version of Record (includes final page, issue and volume numbers)

\section{Please check the document version of this publication:}

- A submitted manuscript is the version of the article upon submission and before peer-review. There can be important differences between the submitted version and the official published version of record. People interested in the research are advised to contact the author for the final version of the publication, or visit the $\mathrm{DOI}$ to the publisher's website.

- The final author version and the galley proof are versions of the publication after peer review.

- The final published version features the final layout of the paper including the volume, issue and page numbers.

Link to publication

\section{General rights}

Copyright and moral rights for the publications made accessible in the public portal are retained by the authors and/or other copyright owners and it is a condition of accessing publications that users recognise and abide by the legal requirements associated with these rights.

- Users may download and print one copy of any publication from the public portal for the purpose of private study or research.

- You may not further distribute the material or use it for any profit-making activity or commercial gain

- You may freely distribute the URL identifying the publication in the public portal.

If the publication is distributed under the terms of Article 25fa of the Dutch Copyright Act, indicated by the "Taverne" license above, please follow below link for the End User Agreement:

www.tue.nl/taverne

Take down policy

If you believe that this document breaches copyright please contact us at:

openaccess@tue.nl

providing details and we will investigate your claim. 


\title{
Planar Circularly Symmetric EBG's to Improve the Isolation of Array Elements
}

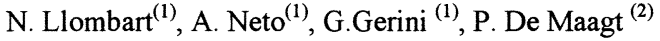 \\ (1) Radar Group, TNO, Den Haag, The Netherlands. \\ E-mail: nuria.llombartjuan, andrea.neto, giampiero.gerini@tno.nl \\ (2) European Space Research and Technology Center (ESTEC), Noordwijk, The \\ Netherlands. E-mail: peter.de.maagt@esa.int
}

\begin{abstract}
Introduction
In a companion paper [1] to be published in the proceeding of this same conference, the use of Planar Circularly Symmetric (PCS) Electromagnetic BandGap (EBG)'s for optimizing the performances of single antenna elements has been presented. Some advantages are obtained using this sort of super structures. First, they are planar and thus not difficult to manufacture with respect to alternative EBG structures based on vertical pins perforating the dielectric [2][3]. Secondly, with respect to other purely planar EBG structures, the surface wave propagation is reduced in all radial directions, thanks to the circular symmetry. Finally, the design of these structures is simple since it is based on the solution of $2 \mathrm{D}$ problem and extension to $3 \mathrm{D}$ geometries [4]. In [1] an antenna with $20 \%$ of bandwidth has been presented which does not suffer from surface wave effects.
\end{abstract}

When the attention is shifted toward the design of phased arrays, the trade offs that guide the requirements are different from those associated to single antennas. Among such requirements, there are typically both, a moderately large bandwidth and a high isolation between the array elements. It appears natural to assume the isolation as leading requirement, since the possibility to achieve it is one of the most characterizing aspects of the EBG technology applied to arrays. Giving priorities to the requirements is important because bandwidth and isolation between elements are often conflicting in scanning arrays. If antenna elements that compose an array are isolated and the array is well sampled at Nyquist interval, each antenna has only a small volume at its disposal. As a consequence the bandwidth of each antenna element coincides with the bandwidth of the array and it is limited by such small volume. When the arrays are composed by elements that are very strongly coupled such bandwidth limitation does not exist as the elements operate all together and each element uses a shared volume larger than that of each elementary antenna. In principle, when the elements are totally coupled the bandwidth of an array can be theoretically infinite as shown in [5].

In this contribution the basic antenna element considered is the same as in [1]. Two possible periodical arrangements of antennas surrounded by their own PCSEBG are shown in fig. 1 , based on one, a), or two, b), rings. The period $p$ indicates the distance between the centers of two antenna elements, $\rho$ represents the 
distance between the center of the antenna and the center of the first ring element, and $d$ is the period of the PCS-EBG structures

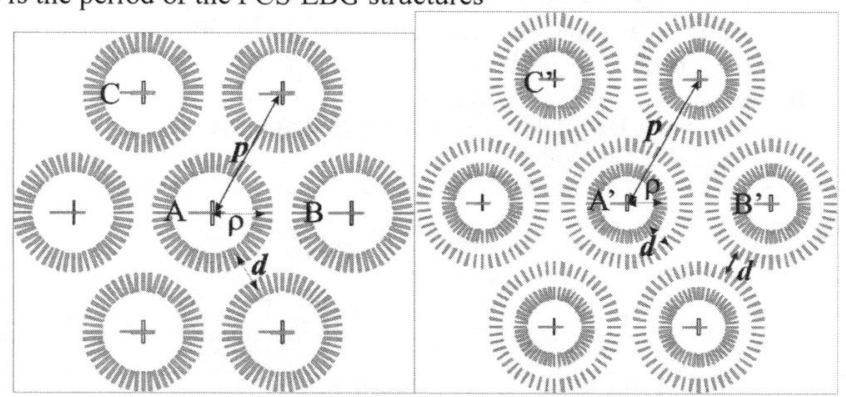

a)

b)

Fig 1 Array configurations based on one, a), or two, b), rings.

If the EBG is designed according to the rules defined in [4] already one ring EBG around each antenna decreases the coupling between different array elements. Two rings around each antenna improve the isolation, while three rings around each antenna are unnecessary. This is because once the $\mathrm{TM}_{00}$ is suppressed the residual mutual coupling occurs via space waves, whose propagation is not altered significantly by the presence of the EBG. Thus, it is the distance between the elements in terms of free space wavelengths that limits the isolation. Accordingly, assuming for simplicity that $\rho \approx d$, from fig 1 a) one can observe that $p \approx 3 d$, while from fig. 1 b) $p \approx 5 d$. If the period $p$ is set to $\lambda_{0} / 2$ in order to obtain the maximum scanning angles one obtains, $d \approx \lambda_{0} / 6$ or $d \approx \lambda_{0} / 10$ for the one or the two rings configuration respectively. If one also considers that when the loading substrate is operated at a frequency inside the band gap region, the propagation constant of the loaded structure, $\beta$ is bound to be $\beta=\pi / d$ then it results $\beta>3 k_{0}$ or $\beta>5 k_{0}$. As explained in [4], the upper limiting value for the propagation constant inside the dielectric is given by the propagation constant of the $\mathrm{TM}_{0 \mathrm{gg}}$ mode in the parallel plate waveguide that is obtained when the metallic loading is continuous, i.e. $k_{0 g g}=k_{0}\left(\varepsilon_{r}\right\}^{1 / 2}$. Accordingly, in the case of an array with 1 ring EBG's, the dielectric constant of the slab must be sufficiently high that $k_{0}\left(\varepsilon_{r}\right\}^{1 / 2}>\beta>3 k_{0}$. In the case of an array with 2 rings EBG's, the equivalent condition is $k_{0}\left(\varepsilon_{r}\right\}^{1 / 2}>\beta>5$ $k_{0}$. Including some margin, these conditions imply the use of $\varepsilon_{r}>16$ for arrays based on one ring elements or $\varepsilon_{r}>25$ for arrays based on two rings elements.

In fig. 2 the $\mathrm{S}$ parameters representing the mutual coupling between antennas arranged in arrays as in fig. 1 are presented as a function of the frequency. The dielectric constant of the slab is $\varepsilon_{r}=20$ and the actual values of the antenna and EBG parameters are designed to be congruent with this dielectric constant, see [1]. For the sake of brevity, only the mutual orientations of the antennas that involve larger surface wave couplings are shown. In particular, fig. 2a compares the $S_{A B}$ and $S_{B C}$ parameters associated to two arrays of antenna elements with and 
without the one ring EBG loadings. In this configuration $p=0.6 \lambda_{0}$ at the highest frequency considered. It is apparent that one ring EBG is capable of reducing the mutual coupling between the antennas of an average of $5 \mathrm{~dB}$ 's even though the $S_{B C}$ presents a rather peculiar resonant behavior. This is most likely due to the fact that despite the improvement one ring is not sufficient to completely reduce the effects of the SW's and this latter still creates unpredictable resonances inside the dielectric slab.

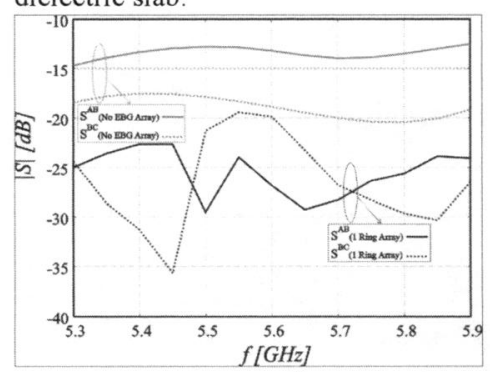

a)

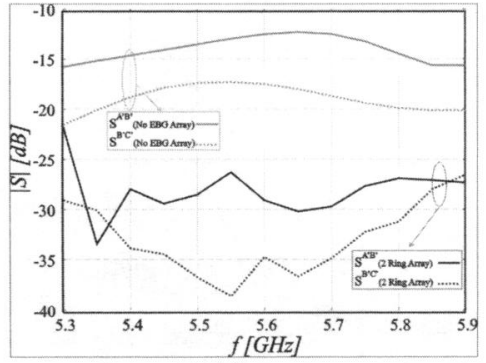

b)

Fig. 2. S parameters representing the mutual coupling between antenna elements in the array configurations of fig. 1

Fig. 2b compares the $S_{A^{\prime} B^{\prime}}$ and $S_{B^{\prime} C^{\prime}}$ parameters associated to two arrays of antenna elements with and without the two rings EBG loadings. In this case the distance between the centers is larger since the dielectric constant remains the same $\left(p=0.9 \lambda_{0}\right.$ at the highest frequency considered). The two ring EBG configuration is capable of reducing the mutual coupling between the antennas more drastically also eliminating the significant oscillations in the curves that were noticeable in fig. 2 a.

\section{Bandwidth of an antenna printed on a mono-mode dielectric substrate}

Using high dielectric constants allows the isolation between array elements to be improved to the level implied by the space wave coupling. Nevertheless, antennas printed on dense dielectrics present significant bandwidth problems. Fig. 3 presents the percentile bandwidth (taken as the $-10 \mathrm{~dB}$ reflection coefficient band width) as a function of the dielectric constant for antennas as the ones in fig. 1 of [1]. The solid curve summarizes the results theoretically predicted by a commercial MoM tool for a series of similar antennas. Each antenna is a microstrip excited, slot coupled dipole. The antennas are all printed on single dielectric slabs whose dielectric constant is varied and the height, $h$ is such that $h<\lambda_{d} / 4$, with $\lambda_{d}$ the wavelength in the dielectric. This condition ensures that only the $\mathrm{TM}_{00}$ mode is above cut off. From the results it is apparent that the bandwidth is significantly reduced for higher values of the dielectric constant. When the antennas are surrounded by a properly designed EBG (single points at $\varepsilon_{r}=9.8$ and $\varepsilon_{r}=20$ ) the bandwidths are improved but still define a decreasing curve as the dielectric constant increases. The results obtained for dielectric constant equal to 
20 indicate a bandwidth in the order of $10 \%$. One can note that with respect to the results presented in [1] the bandwidth is reduced by a factor 2 . These results are valid only for a specific antenna type, but the decreasing bandwidth behavior is certainly representative for any planar antenna.

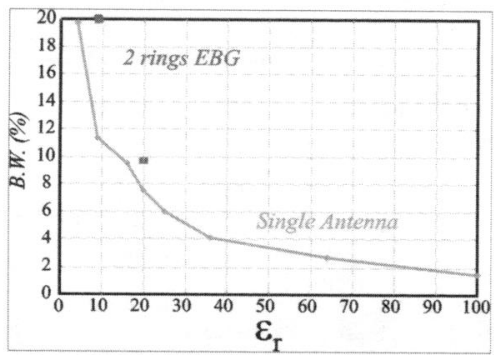

Fig. 3 Percentile Bandwidths of microstrip fed, slot coupled dipoles as a function of the dielectric constant

\section{Conclusions}

A trade off has to be made between bandwidth and isolation of array elements when designing phased arrays. When the isolation is achieved via a PCS-EBG that is aimed at reducing the $\mathrm{TM}_{00}$ mode only, the reduction of bandwidth could be even more important rather than the one obtained when using a more standard cavity backing. This is due to the need of using a higher dielectric constant.

\section{References:}

[1] N. Llombart, A. Neto, G.Gerini, P. De Maagt "Enhanced Antenna Performances Using Planar Circularly Symmetric EBG's" Proceeding of the IEEE Antennas and propagation Symposium, 3-8 July 2005, Washington

\{2] P. de Maagt, R. Gonzalo, Y.C. Vardaxoglou, J.M. Baracco; "Electromagnetic bandgap antennas and components for microwave and (Sub)millimeter wave applications" IEEE Transactions on Antennas and Propagation, Vol. 51, no. 10, pp. 2667-2677, Oct 2003.

[3] D. Sievenpiper, L. Zhang, R.F. Broas, N.G. Alexopolous, E. Yablonovitch, "High-impedance Electromagnetic Surfaces with a Forbidded Frequency Band", IEEE Transactions on Microwave Theory and Techniques, Vol. 47, no. 11, pp. 2059-2074, November 1999.

[4] N. LLombart, A. Neto, G. Gerini, P.J. de Maagt "Planar Circularly Symmetric EBG structures: Design and Analysis" European Microwave Week, Amsterdam, The Netherlands, October 2004.

[5] A. Neto, J. J. Lee, "Infinite Bandwidth Long Slot Array Antennas," To be published in IEEE Antennas and Wireless Propagation Letters, 2005. 